\title{
OBSERVATIONS ON BLINK REFLEXES
}

\author{
GEOFFREY RUSHWORTH
}

From the Neurological Research Unit, Churchill Hospital, Oxford

A reflex wink, which resulted from a tap over the supraorbital region of the face, was described by Overend (1896). He observed that the reflex was the product of facial stimulation, for it was present in the blind. In the 25 years following this discovery it was realized that reflex winking (unilateral contraction of the homolateral orbicularis oculi) or blinking (bilateral contraction) could be elicited from many areas of the face, and some of these facial reflexes became incorporated into the routine examination of the nervous system (Weingrow, 1933). Wartenberg (1945) has admirably described the confusion that has resulted from the failure to recognize the essential identity of the facial reflexes, irrespective of the region of facial stimulation. He proposed that the term 'orbicularis oculi reflex' could well replace the long list of facial reflexes named after their illustrious discoverers, among them, McCarthy (1901), von Bechterew (1902), Weisenberg (1903), Guillan (1920), and Simchowicz (1922). The orbicularis oculi reflex was a simple myotatic reflex, Wartenberg believed, the result of brief stretch of facial musculature. This view was contrary to the generally accepted teleological opinion that a blink (in response to a facial stimulus) was a defence mechanism, designed to protect the eye from damage. However, Kugelberg (1952) conveniently reconciled both these views when he demonstrated, by electromyographic methods, that the blink reflex in response to a facial tap had two components, an initial proprioceptive (myotatic) reflex and a later nociceptive (defence) reflex.

Kugelberg's detailed study confirmed Wartenberg's contention that the blink reflex was the same, no matter which area of the face was stimulated. Ekbom, Jernelius, and Kugelberg (1952) showed that the orbicularis oris reflex had many features in common with the blink reflex. The proprioceptive component of the facial reflexes raised again the question of the situation and nature of the sensory endings which were stimulated, and their afferent pathway. Whereas the afferent fibres of skeletal muscle form almost $50 \%$ of the muscular nerve (Adams, Denny-Brown, and Pearson, 1953), the facial nerve (of the cat) contains only $16 \%$ of sensory fibres and they are mostly of small diameter (Foley and DuBois, 1943). They have been described in human facial nerves by van Gehuchten (1906), by Edgeworth (1900), and by Wakeley and Edgeworth (1933). Bruesch (1944) demonstrated a few large afferents in the facial nerve of cats but found that they entered by the auricular nerve and were probably cutaneous in origin, and Van Buskirk (1945) confirmed this. Apart from taste afferents, the small afferent nerve fibres of the facial nerve were found to terminate near blood vessels of the facial musculature, and the anatomists concluded that they were pain receptors. The negative anatomical evidence is therefore disappointing, for there have been many clinical observations on proprioception in the face which indicate the presence of such afferents in the facial nerve (Ivy and Johnson, 1907; Davis, 1923; Souques and Hartmann, 1924; Carmichael and Woollard, 1933; Rushworth, 1960).

A blink may also result from a light stimulus, and from an auditory stimulus as well as from facial taps. It is the purpose of the first part of this paper to compare and contrast these reflex responses. The response to glabella tap has been particularly studied, as it is the best known of the facial reflexes (apart from the corneal reflex) and is still often employed by clinical neurologists in Great Britain. In the second part of the paper it will be shown how disease of the nervous system and of individual cranial nerves may affect the blink reflexes and their latencies. The third part of the paper will deal with some experiments on the origin, nature, and pathways of the afferents responsible for the reflex to glabella tap.

\section{METHODS}

Glabella tap was performed by tapping a circular metal plate, $1 \frac{1}{4}$ in. in diameter, which was placed over the glabella. The stimulus was therefore rather diffuse and not painful. A metal thimble was used to tap, and contact between it and the metal plate completed a circuit which triggered the suppressed beams of a cathode ray oscilloscope. The same device provided a loud click stimulus when placed directly over an ear.

The cornea was stimulated with a small loop of stainless steel wire, and the contact it made with the cornea completed a circuit which triggered the sweeps of a cathode ray oscilloscope.

Supra-orbital nerves were stimulated through the skin 
with silver electrodes $1 \mathrm{~cm}$. apart, tripolar with a central cathode. Minimal skin preparation usually resulted in a rather high threshold and the shocks were transformer coupled, $0.5 \mathrm{msec}$. duration, and usually $50 \mathrm{v}$. in amplitude with a repetition rate of $1 / \mathrm{sec}$., provided by a Disa Multistim.

An electronic flash was the light stimulus (flash duration $200 \mu \mathrm{sec}$. approximately, peak output 15 to 20 megalumens). The eyes were stimulated separately by covering one of them. The flash itself triggered the sweeps of the cathode ray oscilloscope by means of a photoelectric cell (time lag less than $20 \mu \mathrm{sec}$.).

The responses to all these stimuli were recorded as an electromyogram, with coaxial needle electrodes which were placed in both right and left orbicularis oculi muscles. After conventional amplification they were displayed simultaneously on a double-beam cathode ray oscilloscope, the sweeps of which were photographed on moving photographic paper.

The blink reflexes were studied in 70 subjects varying in age from 9 to 80 years, who were patients of the neurological department. Completely normal responses were therefore studied in only about one-half of these patients, who had disabilities unrelated to the facial region. The subjects lay on a comfortable couch in a darkened room.

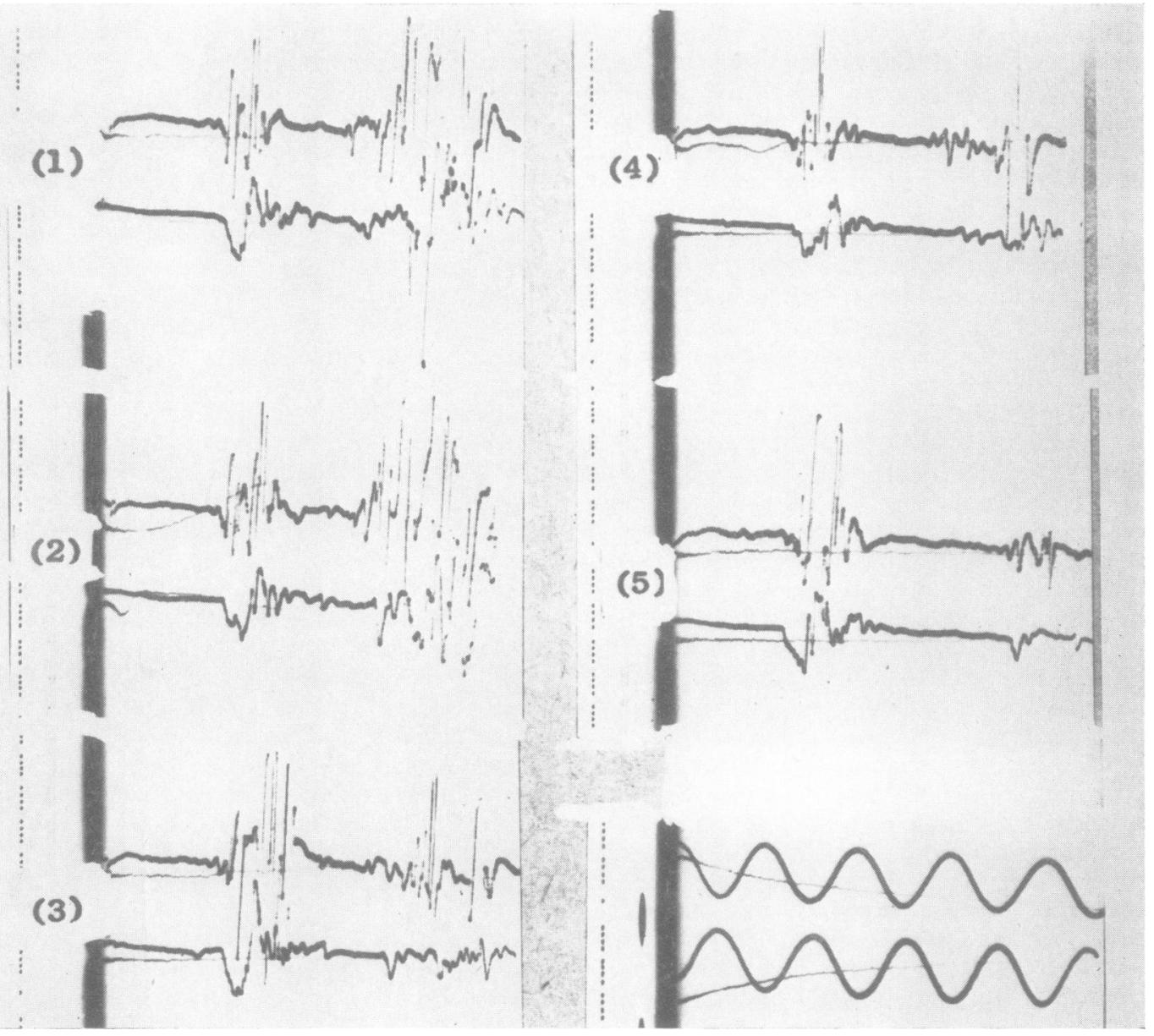

FIG. 1. Blink reflexes to glabella tap. (1) to (5) Five successive taps to the glabella at about 1 sec. interval between each in a normal subject. Two components of the response were elicited each time. The first component was constant in latency and duration, and its amplitude changed little. The second component, however, became progressively smaller in amplitude and of longer latency; this is habituation.

Electromyogram recordings from the right and left orbicularis oculi muscles, upper and lower tracings respectively. This order is maintained in all the illustrations for this paper. Calibrations, 300 microvolts and 100 c.p.s. (10 msec.) unless otherwise stated. 


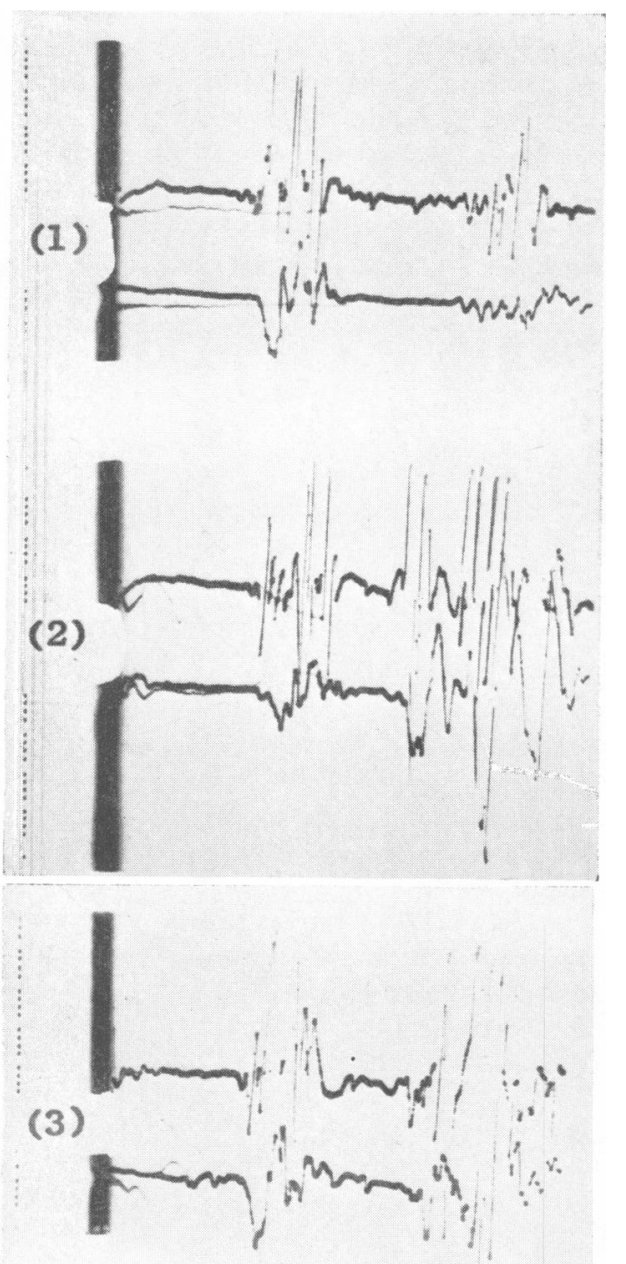

PART I: THE BLINK REFLEXES

THE REFLEX TO GLABELLA TAP In confirmation of Kugelberg (1952), two reflex discharges were usually recorded in the orbicularis oculi muscles in response to glabella tap. It was not possible to separate the two components by altering the strength of the stimulus, though their size was somewhat dependent on this. The threshold was remarkably low; a very light tap gave a good (and often maximal) response. The reflex was unaffected by xylocaine infiltration of the skin under the metal plate, so that the skin immediately over the glabella seems to play little part on the afferent side of this reflex. The stimulus is diffuse and must stimulate at a distance by the transmitted concussive wave. Application of the stimulus to the vault of the skull or to the occipital region was ineffective in eliciting the reflex unless the stimulus intensity was greatly increased.

The subject was requested to keep the eyes lightly closed, and the tap stimulus was applied by hand at about $1 /$ second until about 20 responses had been recorded. The reflex to the first tap of the series almost invariably showed the two components (Fig. 1), one synchronous (lasting 5 to $7 \mathrm{msec}$.) discharge at about $15 \mathrm{msec}$. and a second more asynchronous one (lasting 15 to $30 \mathrm{msec}$.) at about $26 \mathrm{msec}$. With subsequent stimuli, the first response occurred with a latency fixed within $\pm 0.5 \mathrm{msec}$. and of relatively constant amplitude. The second reflex component, however, changed in both latency and amplitude with each repeated stimulus, the latency becoming longer and the amplitude less (Fig. 1, 2 to 5). This is habituation and typical of a nociceptive reflex in a subject who begins to realize the innocuous nature of the repeated stimulus. When habituation was established, the second reflex component was restored to early latency and large amplitude simply by suggesting to the subject that the stimulus would be painful, though in fact the same stimulus was delivered (Fig. 2). The suggestion that the subject would receive an electric shock applied through skin electrodes on the dorsum of the hand had the same effect in shortening the latency of the second component of the blink reflex, irrespective of whether the shock was given or not.

The first component of the blink reflex varies little in latency from individual to individual. In Fig. 3 the distribution of its latency in 38 patients is plotted and shows a range from 11 to $18 \mathrm{msec}$. with a peak at 14 to 15 msec.

The second component has a much wider range

FIG. 2. Recordings as in Fig. 1, same subject. (1) Habituated response; (2) and (3) after the subject had been told that the tap might be painful, though in fact the same stimulus was delivered. The second response returned at an early latency and with large amplitude. of variation from 23 to 60 (or longer) msec., but most responses are between 27 and $40 \mathrm{msec}$. 


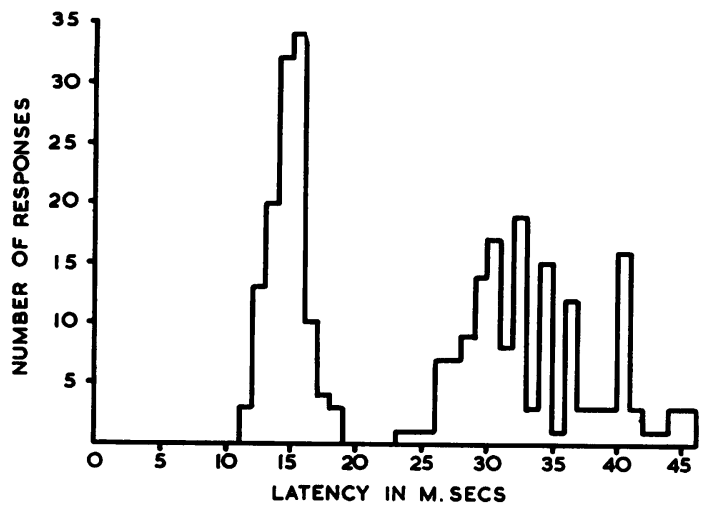

FIG. 3. The variation of the latencies of the two responses to glabella tap in 38 patients.

REFLEX TO ELECTRICAL STIMULATION OF SUPRAORBITAL NERVE This reflex bears many resemblances to the response to glabella tap.

Unilateral maximal stimulation produced a homolateral discharge in the orbicularis oculi which had two components and there was often a contralateral reflex which was synchronous with the second component (Fig. 4). The latency of the first discharge was very constant in a given individual; the second showed more variability but did not appear to habituate. The latencies of these components in 24 subjects is plotted in Fig. 5. On the whole, the latencies are 2 to $4 \mathrm{msec}$. shorter than the reflexes to glabella tap. By altering the strength of stimulus it was possible to separate the two components. The homolateral first component was elicited by shocks of low intensity, but when the strength of stimulus was increased the second component appeared simultaneously both on the homolateral and contralateral side.

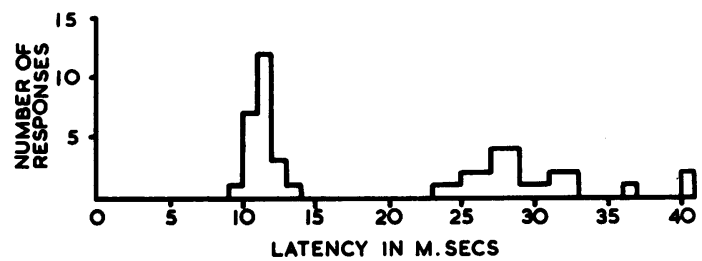

FIG. 5. The variation of latency of the two responses to electrical stimulation of a supra-orbital nerve in 24 subjects.

THE CORNEAL REFLEX A light touch to the cornea with a minute wire loop resulted in a reflex discharge of the orbicularis oculi bilaterally. It was a long asynchronous discharge with a variable latency between 25 and $40 \mathrm{msec}$., and was thus within the same latency range as the second component of the glabella tap reflex.

THE REFLEX TO A CLICK A loud click applied directly

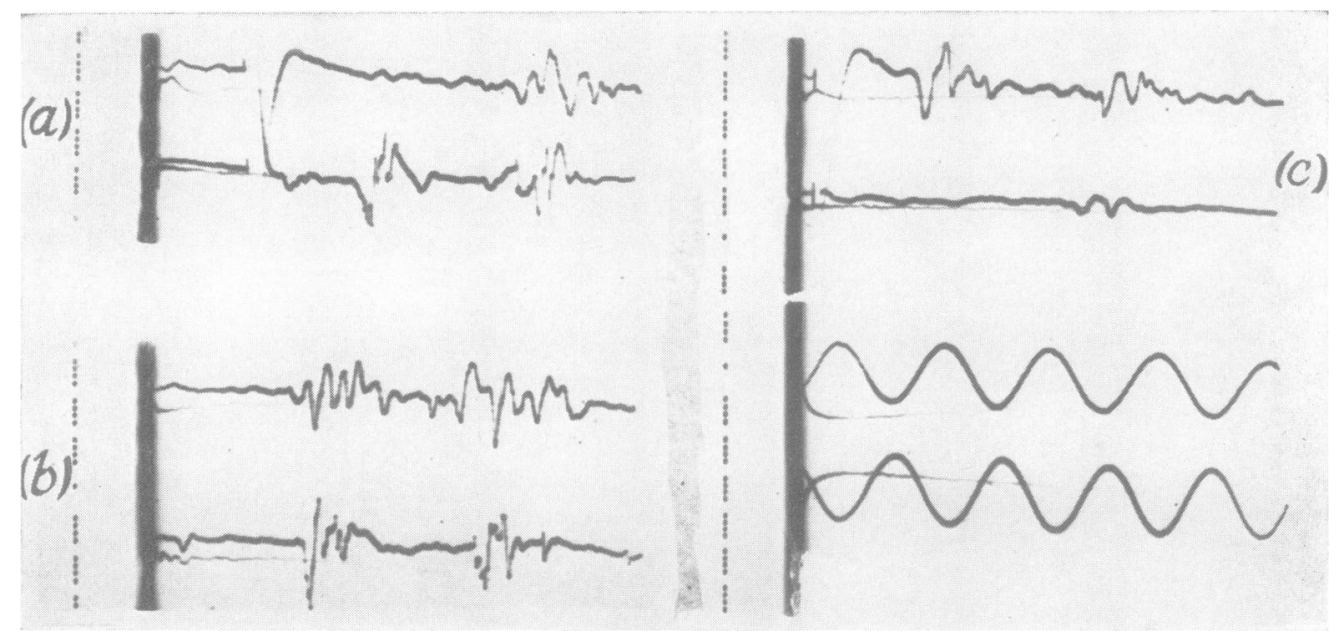

FIG. 4. Blink reflexes to electrical stimulation of a supra-orbital nerve. (a) Near-maximal stimulation of the left supra-orbital nerve resulted in two responses on the left (lower), but only a second component on the right (upper). The bilateral second components were approximately simultaneous. (b) The response to glabella tap, in the same subject, to show the similarity of reflex organization and latencies. (c) Stimulation of the right supra-orbital nerve. 


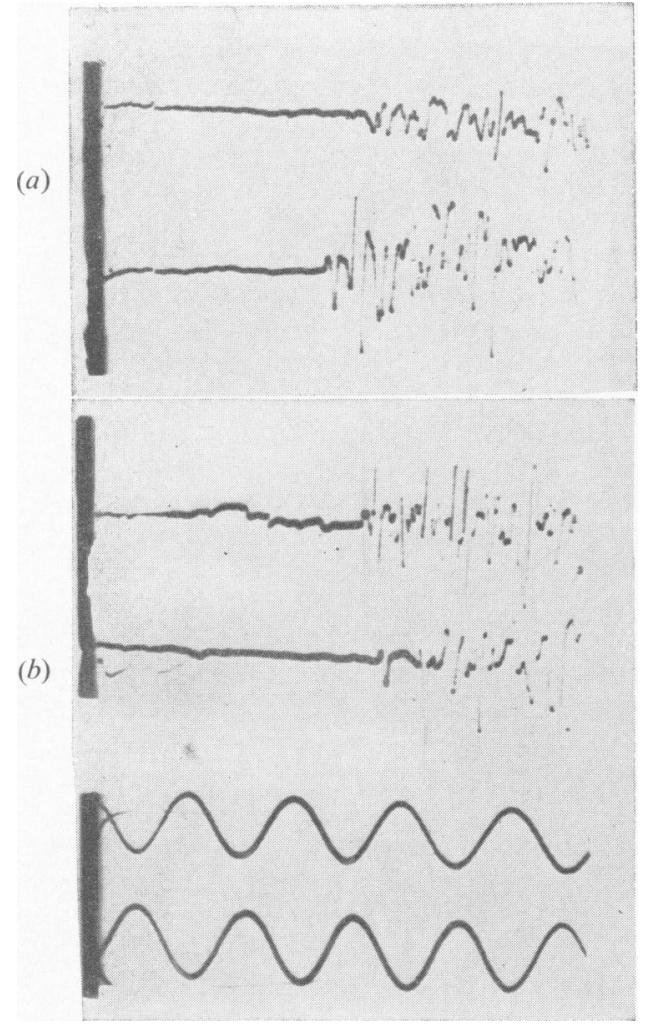

FIG. 6. Blink reflexes to clicks. (a) Click over the left ear produced an earlier response of the left orbicularis oculi (lower). (b) Click over the right ear produced an earlier response of the right orbicularis oculi (upper).

to the ear evoked a blink. The electromyogram showed that the latency was less in the orbicularis oculi on the side of stimulation (Fig. 6). The reflex to a loud click habituated slowly, an increase of latency and a decreased response occurred only after about the tenth stimulus. Spontaneous fluctuations of latency were, however, frequent. Latency of response has been plotted, on a frequency curve, for

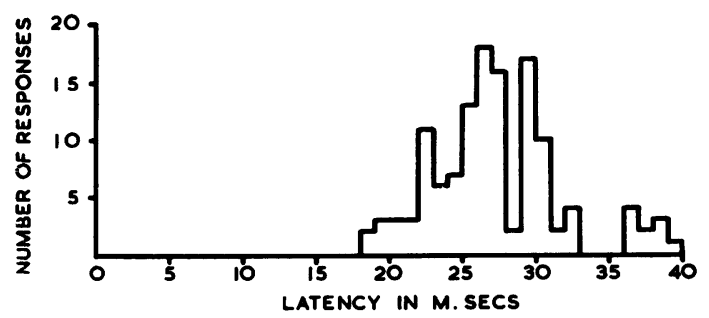

FIG. 7. The variation of the latency of the responses to clicks in 24 subjects.
24 subjects (Fig. 7), and it shows that the great number of responses occurred between 23 and 30 msec., rather shorter than the second component of the reflex to glabella tap.

Clicks made near the patient, but not directly over the ear, did not elicit a reflex blink.

THE REFLEX TO A FLASH OF LIGHT Many types of light flashes were used as stimuli at the beginning of this study, but it was soon found that flashes delivered from an electric torch were not only

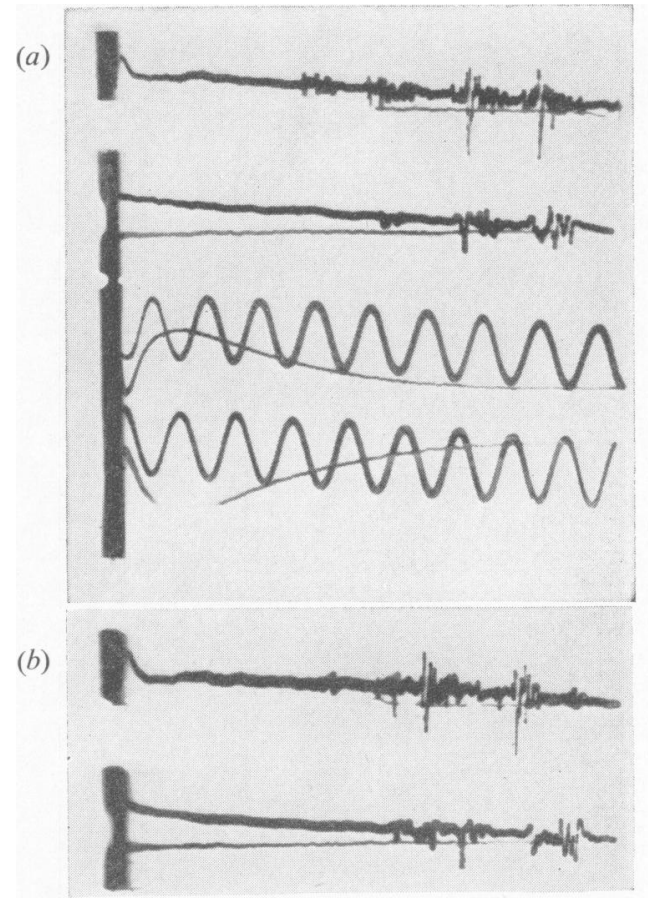

FIG. 8. The blink reflexes to a bright flash of light. (a) Stimulus to left eye alone. (b) Stimulus to right eye alone. The right orbicularis (upper record) responded first on both occasions.

unsuitable because of their physical properties, but also because most subjects did not blink more than once in response to this stimulus. The electronic flash was found to be an effective stimulus to a blink in most subjects, but occasionally normal subjects do not respond to it, probably because of its brevity.

The reflex blink in response to a bright flash of light showed more variability of latency and of component groups than the blink reflexes to other stimuli. Often the latency of the first response was shortest in the right orbicularis oculi, irrespective of the eye stimulated (Fig. 8). The subjects who showed this best had also a dominant right eye. 


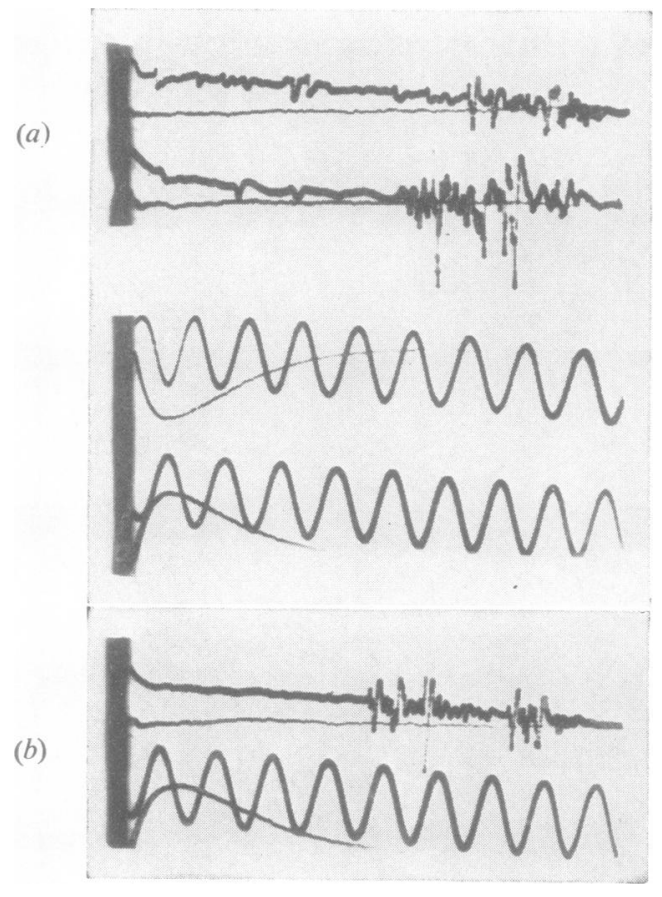

FIG. 9. The less common type of response to bright flashes of light. (a) Right eye stimulated alone produced earlier reflex in the left orbicularis. (b) Left eye stimulated alone produced earlier reflex in the right orbicularis.

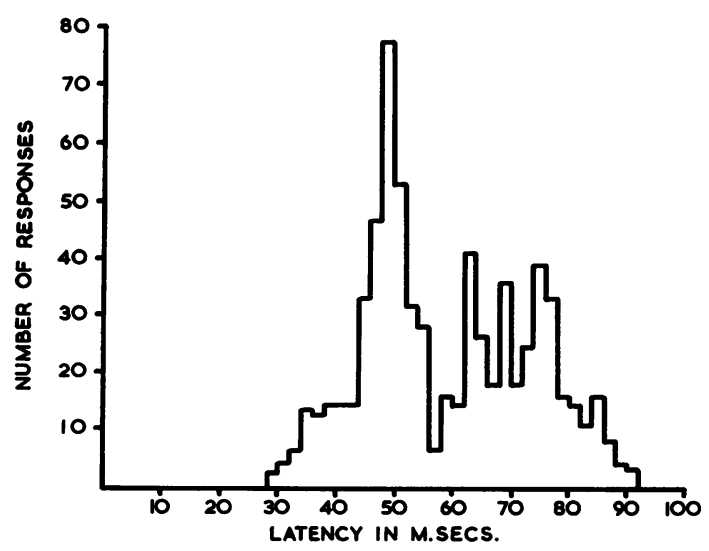

FIG. 10. The variation of response latencies in response to a bright flash of light in 20 subjects.
Occasionally, there was a crossed relationship stimulation of the right eye, giving an earlier response in the left orbicularis oculi and vice versa (Fig. 9).

The latency of over 600 responses in 20 patients has been plotted as a distribution curve (Fig. 10). There is a sharp peak at about $50 \mathrm{msec}$. and less marked ones at 64,68 , and $76 \mathrm{msec}$. Indeed, it was quite common to record all these four components simultaneously (see Fig. 7).

The apparatus which delivered the light stimulus gave an audible click simultaneously with the flash. It would appear, however, from the paucity of responses in the 20 to $30 \mathrm{msec}$. region, that the click was not of sufficient intensity to elicit a blink reflex itself. This point was also checked in control runs when the patient was blindfolded.

Repeated applications of the flash stimulus resulted in a marked decrease of response amplitude after about eight stimulations provided they were at regular (and predictable) intervals. With an irregular rate of stimulation this type of habituation was not observed.

PART II: EFFECTS OF DISEASE OF INDIVIDUAL CRANIAL NERVES AND OF THE CENTRAL NERVOUS SYSTEM ON BLINK REFLEXES

PARTIAL OR RECOVERING FACIAL (BELL's) PALSY All the blink reflexes have the motor component of the facial nerve as their final common pathway. Lesions of the facial motor nucleus and its efferent fibres will have, therefore, a profound effect on all the blink reflexes, and in a total lesion they will be lost.

In 14 patients with partial acute Bell's palsy (the 'neuropractic' type of lesion which tends to recover quickly) and in the recovery phase of the more severe Bell's palsy (which recovers by regeneration), the two components of the blink reflex to glabella tap could usually be elicited. Their latency, however, was greatly delayed compared with the normal side (Fig. 11), and the number of motor units firing in each response was greatly reduced. The motor response was then made up of one or two polyphasic action potentials of long duration $(6 \mathrm{msec}$. and above).

The delay in latency of the first component was between 5 and $10 \mathrm{msec}$. longer than on the normal side. The delay of the second component was not quite so marked, and varied between 4 and $8 \mathrm{msec}$. When the subject anticipated a painful stimulus, the latency of the second component, even on the abnormal side, was shortened (Fig. 11) but equality with that on the normal side was not obtained.

Electrical stimulation of the supra-orbital nerves, loud clicks, and flashes of light all produced blink 


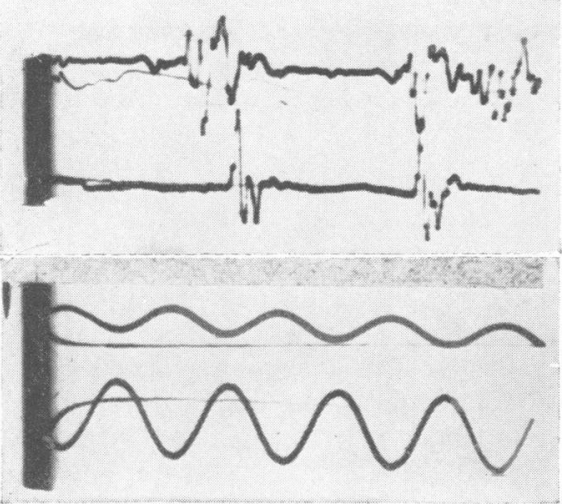

FIG. 11

(a)

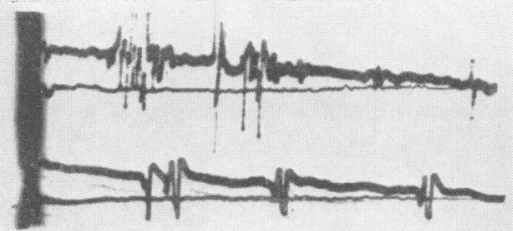

(b)

(c)

(d)
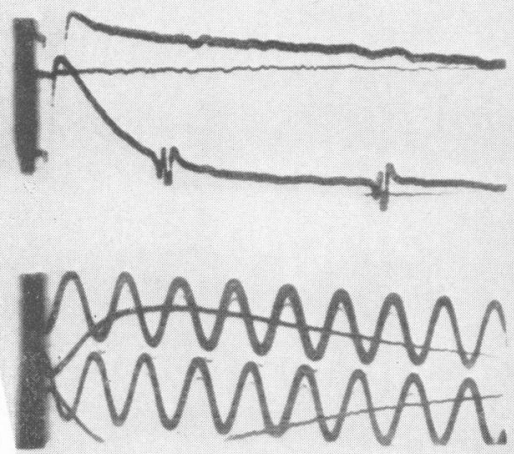

(a)

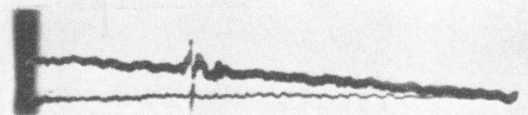

(b)

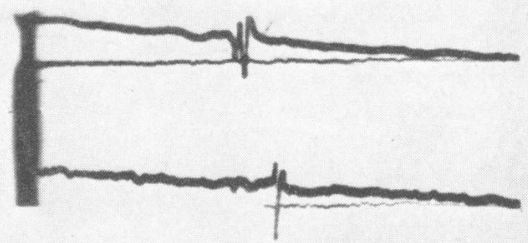

(c)
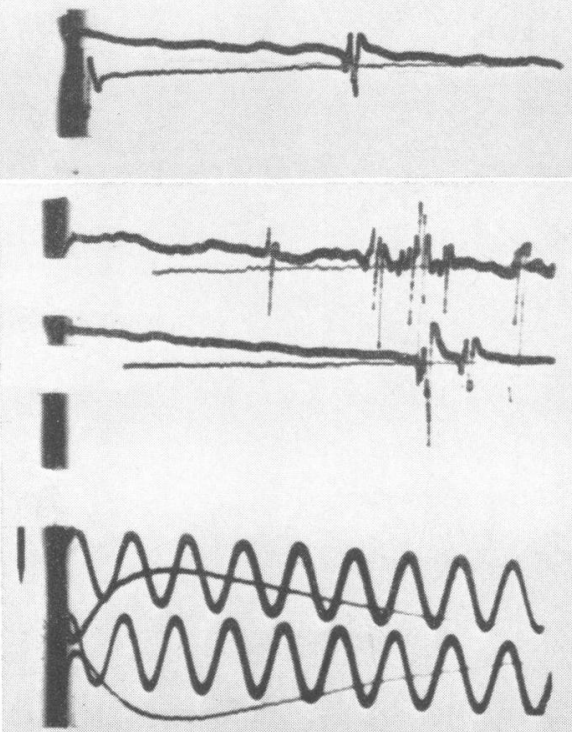

FIG. 13

FIG. 11. Reflexes to glabella tap in partial left facial palsy. There were longer latencies of both responses on the left, a greater delay for the first response than for the second.

FIG. 12. Left partial facial palsy. (a) Reflexes to glabella tap. There was delay of the first and second component on the left, even when the second component was potentiated by a suggestion of a painful stimulus. (b) Single polyphasic units of long duration made up the motor response on the paretic side. (c) Stimulation of the right supra-orbital nerve elicited a normal response in the right and nothing in the left orbicularis oculi. (d) Stimulation of the left supra-orbital nerve elicited two responses on the left, with greatly increased latencies.

FIG. 13. Reflexes to click in a patient with left partial facial palsy. (a) Response to stimulation of right ear. (b) Response to stimulation of left ear. (c) Reflexes to flash. There was a regular longer latency of the responses on the left. 

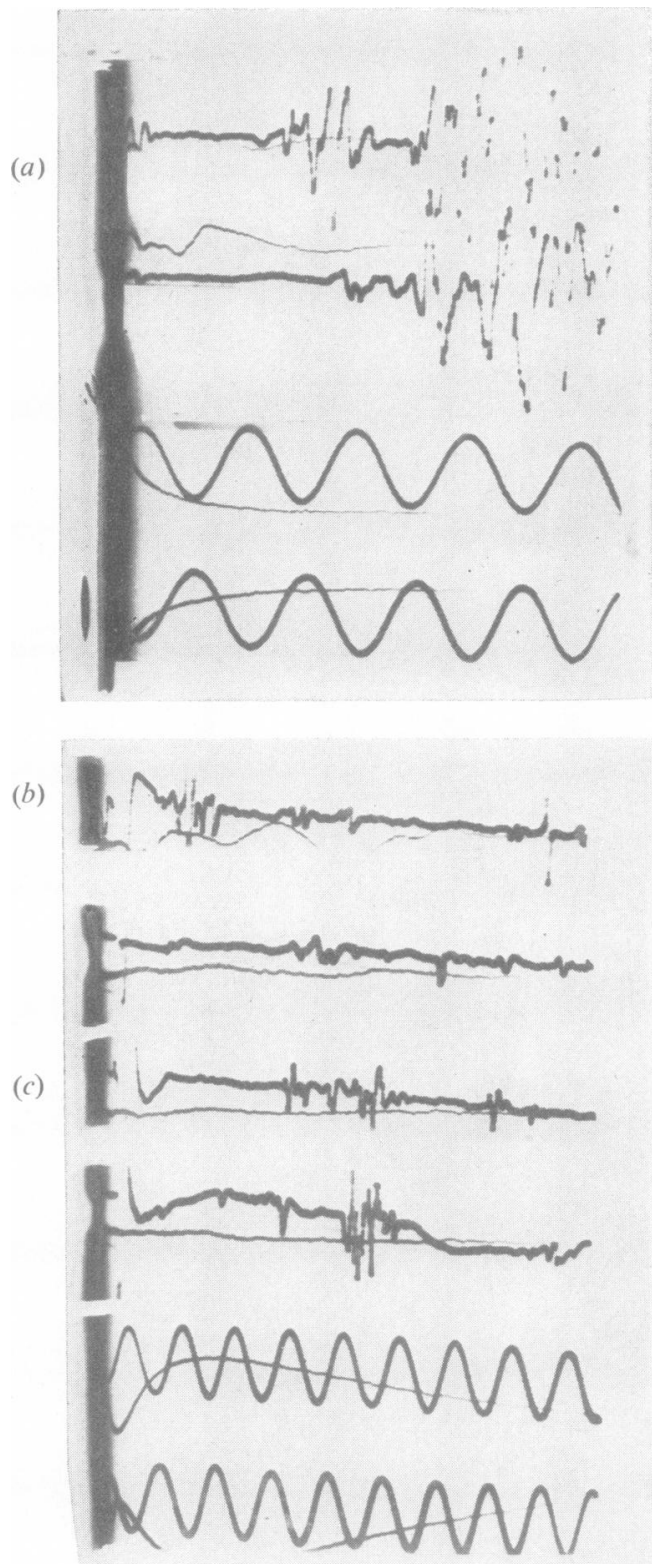

FIG. 14. Partial left trigeminal lesion (first division). (a) Reflexes to glabella tap. First component was small and of delayed latency. Second component was normal and of equal latency with that of the normal side. (b) Stimulation of right supra-orbital nerve elicited two responses on right and a small second component on left. (c) Stimulation of left supra-orbital nerve elicited a second component only bilaterally. reflexes which were delayed on the paretic side compared with the normal (Fig. 13). The increased latency on the paretic side amounted to about 4 to $8 \mathrm{msec}$. The same long-duration polyphasic action potential represented the motor response in each reflex.

OPTIC ATROPHY AND HEMIANOPIA Eight patients with unilateral primary optic atrophy were studied. A consistently delayed latency of the blink reflex, on stimulation of the abnormal eye with a bright flash of light, has not been demonstrated. Several of these patients showed no blink response to such stimulation, and the others blinked with a latency not significantly different from the normal side.

In patients with hemianopia, blink reflexes of normal latency were obtained in response to a bright flash of light.

TRIGEMINAL NERVE LESIONS In seven patients with partial unilateral trigeminal nerve lesions both the blink reflexes to glabella tap and to electrical stimulation of the supra-orbital nerves showed profound changes in reflex amplitude, and latency on the abnormal side. The response to glabella tap either showed no first component on the abnormal side or a tiny first component which was delayed by about 5 msec. (Fig. 14). The second component was of normal latency and amplitude.

Electrical stimulation of the supra-orbital nerve on the abnormal side produced reflex responses in the homolateral orbicularis oculi which had latencies of about $10 \mathrm{msec}$. greater than the normal side.

The corneal reflex was present and of normal amplitude, but its latency was so variable that it was not possible to demonstrate a definite delayed latency of the reflex.

EIGHTH NERVE LESIONS In five patients with unilatera! partial eighth nerve lesions the reflex blink to a loud click over the normal ear produced a response in both orbicularis oculi which was not quite synchronous, the homolateral orbicularis oculi responding with a latency of $25 \mathrm{msec}$., and the contralateral orbicularis oculi following 1 to $2 \mathrm{msec}$. later (Fig. 15).

When the abnormal ear was stimulated, however, there was a very small response on the homolateral side with $28 \mathrm{msec}$. latency, and the contralateral side followed about $1 \mathrm{msec}$. later. There is thus a delayed latency of $3 \mathrm{msec}$. for the reflex blink on the abnormal side.

PARALYSIS AGITANS (19 cases) The absence of 'fatiguability' of the blink in response to glabella tap is a well-known clinical sign in paralysis agitans. When the response was recorded from such a patient it became clear that the absence of 


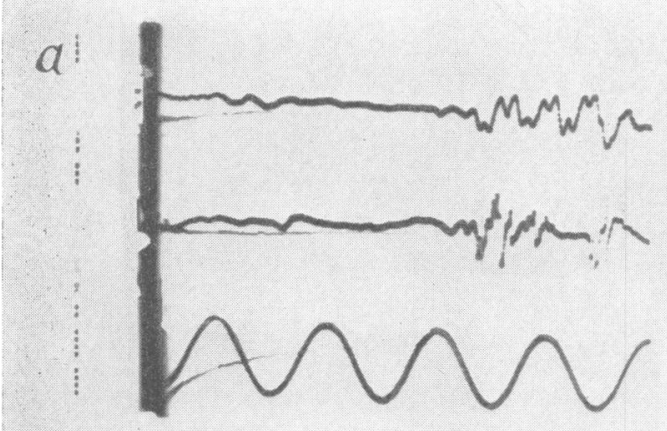

FIG. 15. Reflexes to click in a patient with partial left auditory nerve lesion. (a) Responses to stimulation of the right ear were normal. (b) Responses to stimulation of the left ear showed decreased amplitude on the left and increased latency.

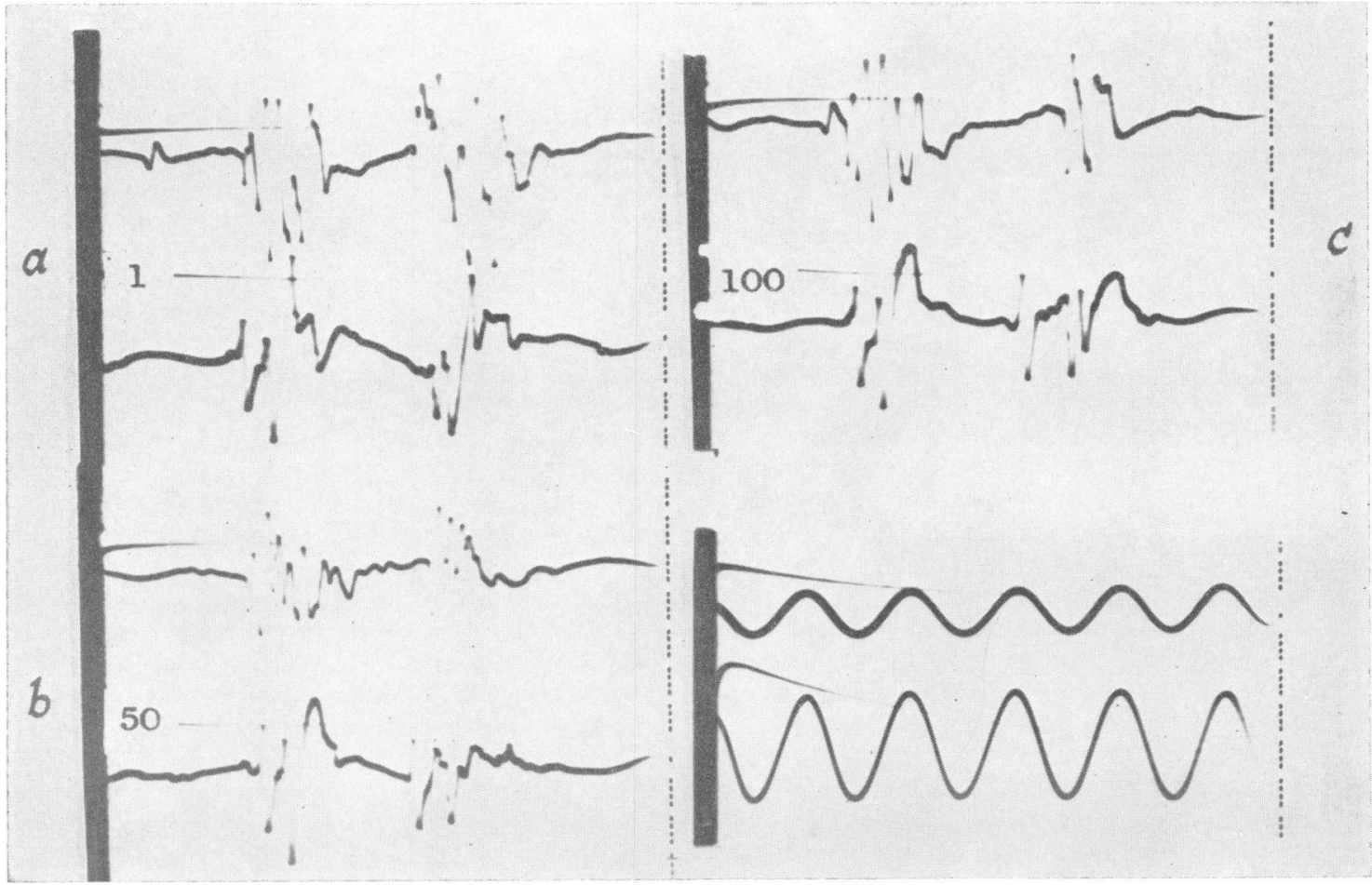

FIG. 16. Blink reflexes to glabella tap in paralysis agitans. (a) Exaggerated first and second components bilaterally. (b) No habituation after 50 stimuli nor (c) after 100 stimuli. Calibrations 1,000 microvolts and $100 \mathrm{c} / \mathrm{s}$.

'fatiguability' was due to the persistence of the second component which did not habituate at all. Whereas, in a normal subject, the second component of the response to glabella tap had become small in amplitude and long in latency by the fourth tap, this component in paralysis agitans had an identical latency even on the fiftieth or one-hundredth stimulus, though its amplitude was slightly diminished (Fig. 16).

The first component of the response to glabella tap was usually of large amplitude in paralysis agitans and in hemi-parkinsonism it was larger on the abnormal side. More important than the size (which might be a recording artifact) was the 


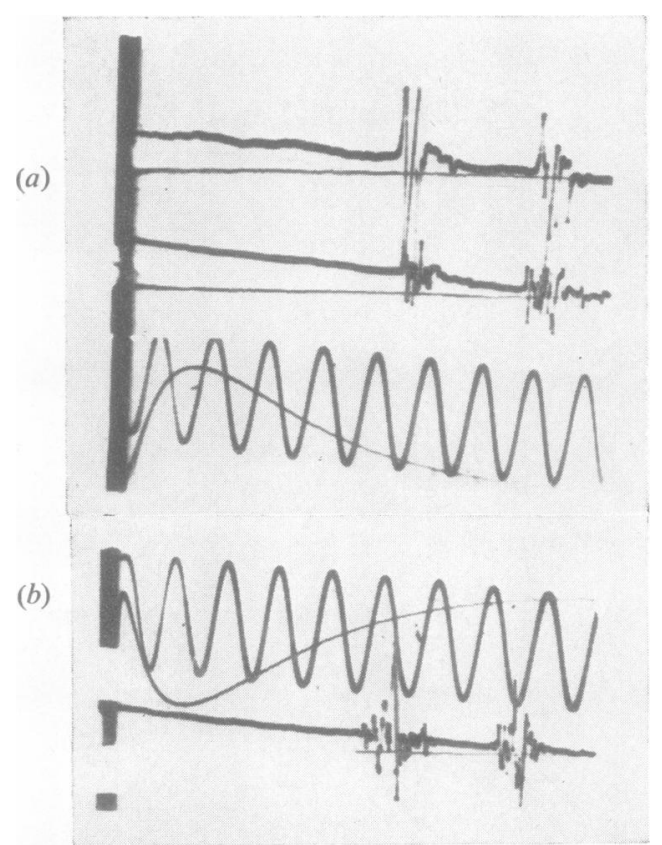

FIG. 17. Blink reflexes to flash in paralysis agitans. (a) Left eye stimulated. (b) Right eye stimulated. Constancy and synchronization of reflexes. Calibrations 1,000 microvolts and $100 \mathrm{c} / \mathrm{s}$.

difference in duration of the reflex, which was over $10 \mathrm{msec}$. (the normal was not over $7 \mathrm{msec}$.).

Extreme constancy of the blink reflexes to clicks and flashes of light were also a feature of paralysis agitans (Fig. 17), and the individual reflexes were remarkably synchronous.

These features were not observed in two cases of drug-induced parkinsonism, nor in two patients with endogenous depression who had some superficial parkinsonian features.

HEMIPARESIS In 10 patients with hemiparesis the first component of the response to glabella tap was increased in amplitude on the abnormal side, and its duration exceeded $10 \mathrm{msec}$.; the second component was relatively small in amplitude, of long latency with rapid habituation.

TETANUS Two patients only were studied; both had severe tetanus and one was also decerebrate as a result of anoxia and cardiac arrest during a spasm. In both patients the first component of the response to glabella tap was of large amplitude and lasted more than $10 \mathrm{msec}$. The second component was not prominent and in the decerebrate child it had a constant latency of $38 \mathrm{msec}$.
PART III: SOME OBSERVATIONS ON THE NATURE, ORIGIN, AND PATHWAYS OF THE AFFERENTS RESPONSIBLE FOR THE BLINK TO GLABELLA TAP

The stimulus employed in the present study was entirely painless and rather diffuse, as it was applied through a $1 \frac{1}{4}$ in. diameter metal plate. The reflex was completely unaffected by dense anaesthetization of the skin immediately under the plate.

In order to study the first component in isolation, a patient was selected who only showed the first component in a rather exaggerated form. After the injection of $10 \mathrm{ml} .2 \%$ xylocaine deeply into the right supra-orbital region (Fig. 18), the reflex response became gradually less until five minutes after the injection, when only one unit responded with an increased latency of $5 \mathrm{msec}$. Five minutes later there was no response on the right to glabella tap, though an electrical stimulus over the right supra-orbital nerve gave a normal response. This would indicate that the receptors responsible for the first component of the response to glabella tap are situated in the homolateral supra-orbital region, probably in the deep tissues. They are comparatively resistant to $2 \%$ xylocaine, for they persist for five minutes after its injection (Fig. 19).

In another patient with left hemi-parkinsonism, who showed the usual two components to glabella tap without habituation, a xylocaine block of the left supra-orbital nerve was successfully carried out. Initially, the first components were identical in latency on the two sides, but the second components were not. On the abnormal side the second component regularly preceded the one on the normal side by $4 \mathrm{msec}$. Following block of the left supraorbital nerve, the first component had been considerably reduced in the left orbicularis oculi by five minutes and had been abolished by 10 minutes. The second component remained unchanged both in amplitude and in latency.

Subsequent deep infiltration of the left supraorbital region had no further effect on the latencies, though the size of the reflexes diminished a little, possibly due to spread of local anaesthetic to the other side.

This experiment indicates that the afferents responsible for the first component of the response to glabella tap pass up the supra-orbital nerve. The second component is either bilaterally represented or travels by another route.

Xylocaine block of both supra-orbital nerves abolished all the reflexes. The block was performed on the right side first, and as soon as the proprioceptive component on the right had been abolished (the second component was still present), a similar block was begun on the left. Within three minutes 


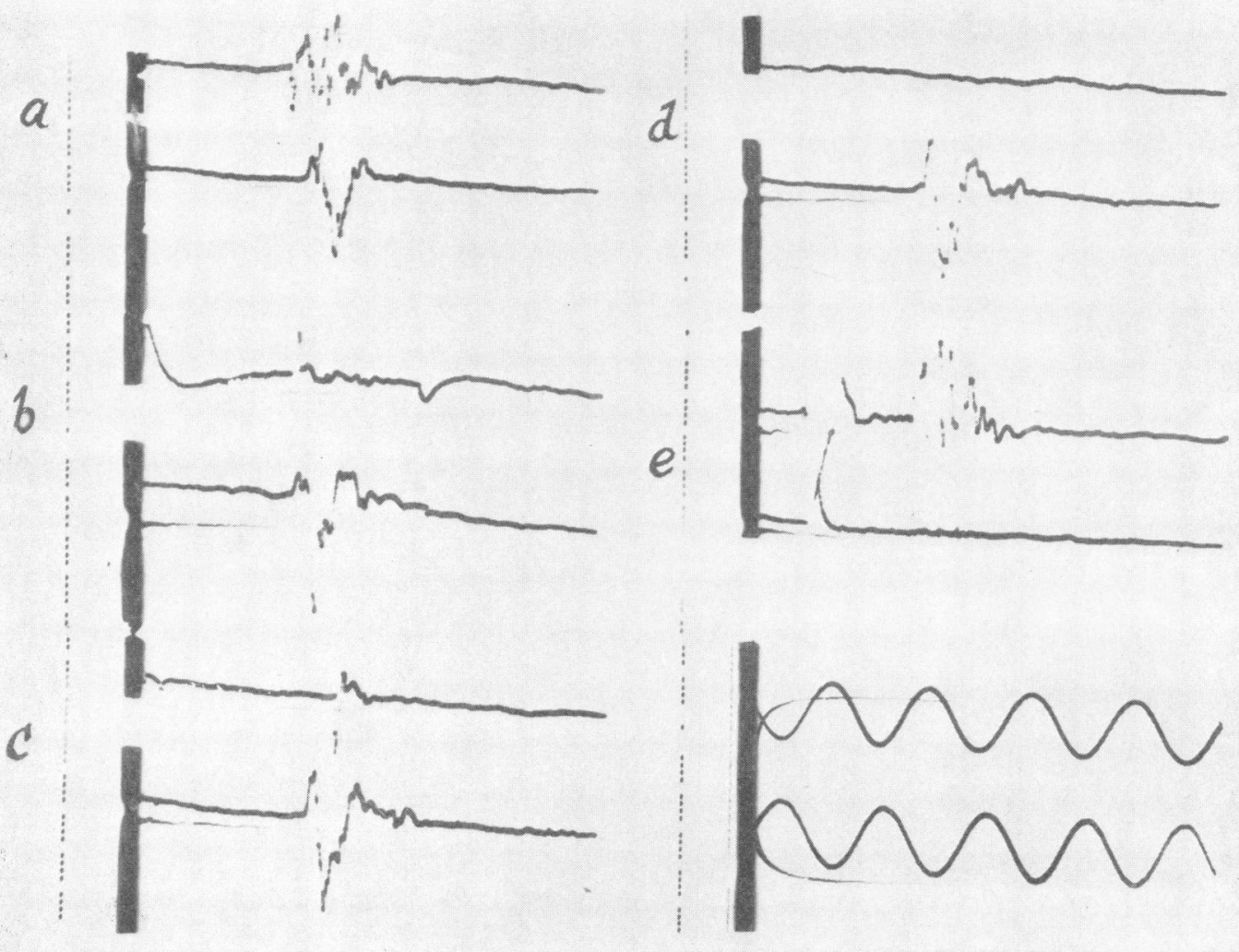

FIG. 18. Reflexes to glabella tap. Progressive effects of $2 \%$ xylocaine injected deeply into right supra-orbital region. (a) Before injection; (b) three minutes after; (c) five minutes after; (d) 10 minutes after; (e) direct stimulation of the right supra-orbital nerve gave a normal response on right, as it was central to the block.

both right and left nociceptive components had disappeared, leaving a small proprioceptive component on the left. After five minutes no reflexes remained on the two sides.

Some of the patients with partial lesions of the facial nerve have shown a response to glabella tap which appears to contain no first component but only a second component (Fig. 20). Proof that it was the second component of the reflex that remained, and not a first component that had been greatly delayed, was provided by the effect of suggesting that the stimulus would be unpleasant. Latency was then shortened by 6 msec., a typical nociceptive response of the second component. This suggests that the first component depends on the integrity of the facial nerve, at least in some patients.

Furthermore, in some cases of facial paresis a comparison between the normal and abnormal orbicularis oculi reflexes to various stimuli has shown that the delayed latency for the first com- ponent of the glabella tap reflex was approximately twice that for the reflexes to click and a bright flash of light. This suggests that both afferent as well as efferent delay occurs in the case of the first component of the glabella tap reflex, and adds yet further evidence for the presence of proprioceptive fibres within the facial nerve in some subjects.

PATHWAYS OF THE OTHER REFLEXes The pathways taken by the afferent volley, which causes a blink to a flash of light, have not been determined. But this blink reflex was absent in a decerebrate child, who blinked in response to glabella tap, corneal stimulation, and to clicks. It was also absent in a patient with cortical blindness due to a large occipital meningioma. It has, however, been absent in a few patients who were not obvious hysterics and who, apparently, had no organic disease of the visual system.

The corneal reflex, the reflex to electrical 


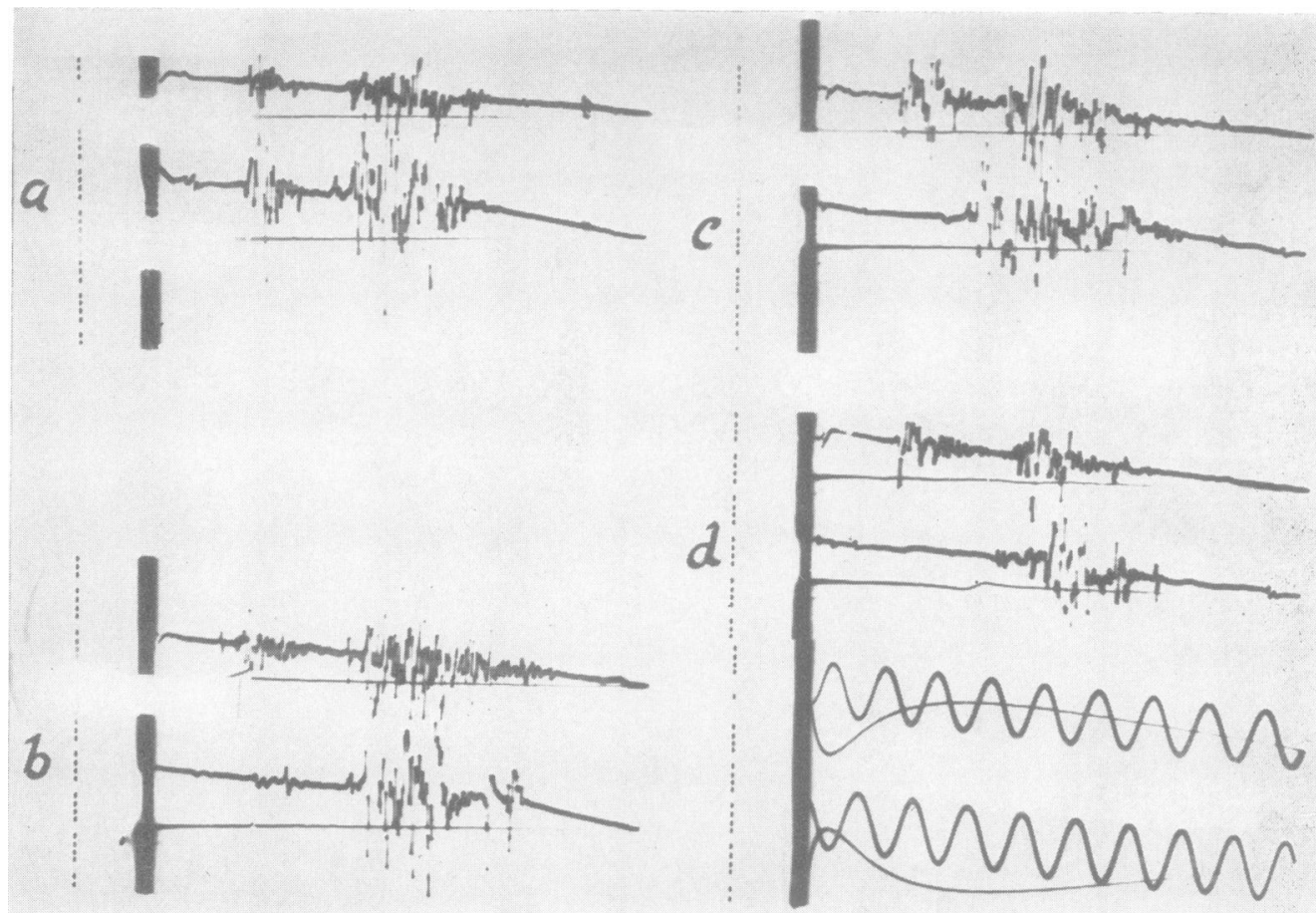

FIG. 19. Effect of xylocaine block of left supra-orbital nerve in a patient with left hemi-parkinsonism. The second component was stable and could not be habituated. (a) Before injection. Longer and larger first and second responses on left. (b) Five minutes after injection of xylocaine. The first response on the left has almost been abolished. (c) Ten minutes after. First response now abolished on left. No effect on second response. (d) Deep infiltration of left-supra-orbital region adds nothing further except a general lowering of reflex amplitude, possibly due to spread of local anaesthetic to the opposite side.

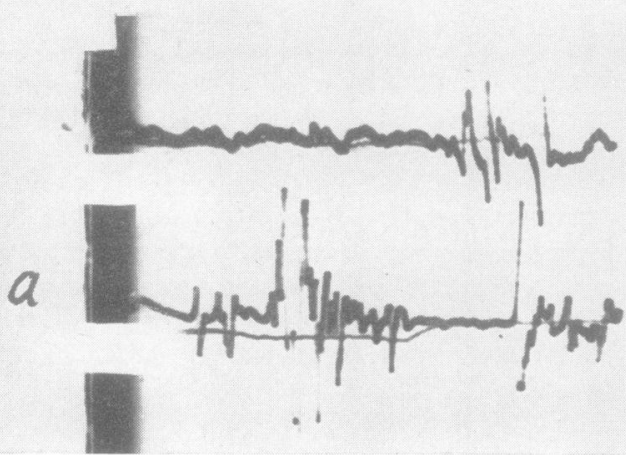

FIG. 20. Partial right facial palsy. Reflexes to glabella tap (an unusual result). (a) No first component on right, but a second component of normal latency is present. (b) Anticipation of a painful stimulus has reduced the latency of the response on the right, proving that it is indeed a second (nociceptive) component and not a greatly delayed first component. This suggests that the facial nerve of this patient normally carries, or influences by gamma efferent innervation, the proprioceptive fibre responsible

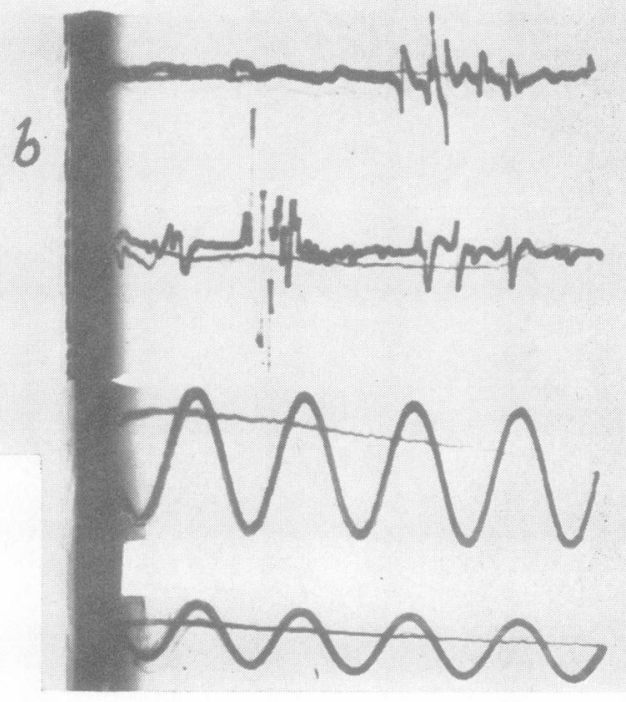

for the first component of the glabella reflex. 
stimulation of the supra-orbital nerves, and the reflex to clicks were all present in a decerebrate boy, and, as their latencies were all within $30 \mathrm{msec}$, one must conclude that they pass through moderately slowly, conducting pathways within the brain-stem.

\section{DISCUSSION}

A number of blink reflexes have been described which are the result of stimulation of end organs within the territory of different cranial nerves. They have all been characterized by their latency, their dispersion in time, by their behaviour to lengthy repetition and to the suggestion that the stimulus might be painful; in all these they show distinctive differences.

REFLEX TO GLABELLA TAP AND STIMULATION OF SUPRA-ORBITAL NERVE Latency measurements of the two components show that the maximum number of responses occurred at $15 \mathrm{msec}$. and about $33 \mathrm{msec}$. Both these figures are a little higher than those given by Kugelberg (1952) for the two components elicited by a tap to the outer corner of the eye. The different site of stimulation, with an increased conducting distance, probably accounts for this discrepancy.

Direct near-maximal stimulation of the supraorbital nerve gives a reflex homolaterally which has two components, and a second component in the contralateral orbicularis oculi. It looks very similar to the response to glabella tap, though the latencies are about $4 \mathrm{msec}$. less. This may well be explained as the difference in stimulating end organs plus a short length of slowly conducting nerve and in stimulating nerve directly. Threshold stimulation of the supra-orbital nerve gives an early homolateral response only, and, as the stimulus is increased, the second component appears simultaneously, both homolaterally and contralaterally. Oka, Tokunaga, Murao, Yokoi, Okumura, Hirata, Miyashita, and Yoshitatsu (1958) describe an almost identical reflex evoked by stimulating either the infra-orbital nerve or the Gasserian ganglion.

These facts, taken in conjunction with the experimental block of the supra-orbital nerve with xylocaine, would lead one to suppose that the afferents responsible for the first component of the glabella tap reflex pass by way of the supra-orbital nerve in most subjects. The persistence of the reflex for five minutes or so after the injection of xylocaine (a rapidly acting local anaesthetic) suggests that the afferent fibres are of large diameter, for these are less affected by local anaesthetics than are smaller nerve fibres (Gasser and Erlanger, 1929; Matthews and Rushworth, 1957). The short latency of this reflex component (15 msec.), the absence of latency fluctuations, the low threshold and synchrony of the reflex (within $7 \mathrm{msec}$.), and the relative constancy of amplitude, all support the thesis that this is a proprioceptive reflex (Wartenberg, 1945; Kugelberg, 1952), probably originating in the facial musculature.

The abolition or delayed latency of the first component of the glabella reflex in patients with a partial trigeminal lesion would lend support to the supposition that the afferent side of the reflex arc follows the supra-orbital nerve into the trigeminal nerve. Occasionally, however, an absent first component with a normal second component has been observed in cases of facial palsy, so that the facial nerve seems to have some effect on the afferent side of the reflex arc, at least in some subjects. If we are dealing with proprioceptors, such as muscle spindles within facial musculature, these should have afferent fibres which might run in the trigeminal nerve, but they might also have gamma efferents from the facial nerve to control the sensitivity of the stretch receptors. A lesion, then, of the trigeminal nerve would abolish the first component because the afferents were interrupted; a lesion of the facial nerve might abolish the first component because the stretch receptors had become relatively insensitive to stretch due to interruption of their gamma motor supply.

This is an attractive hypothesis, but it has little positive support from direct testing so far. When the glabella responses were watched during a progressive xylocaine block of the facial nerve, both the first and second components were abolished together and pari passu with the voluntary power. Furthermore, in two patients with a partial Bell's palsy, the delay of the first component of the glabella response was twice as large as the delayed latency of the blink reflexes to light and to clicks. This would suggest a partial lesion of the afferent as well as efferent nerve fibres within the facial nerves.

The evidence presented here is therefore conflicting and the answer to the problem of the route taken by the afferents responsible for the proprioceptive (first) component of the glabella reflex may depend on individual differences of anatomy. In most subjects they run in the fifth nerve, as Kugelberg (1952) showed, and in a small minority of subjects in the seventh nerve.

The second component of the glabella reflex is an asynchronous response with a variable latency. In normal individuals it rapidly habituates to a response of long latency and small amplitude. The suggestion that the next stimulus will be painful results in a very exaggerated second component of short latency. These features led Kugelberg (1952) to the conclusion that this was a nociceptive reflex, and all the present findings would be in agreement with this view. 
It appears to be a bilateral response, for a bilateral second component can be elicited by electrical stimulation of one supra-orbital nerve. Similarly, the second component to glabella tap is present bilaterally when one supra-orbital nerve is blocked with xylocaine. Bilateral block of the supra-orbital nerves, however, results in abolition of all the glabella responses.

The evidence relating to the afferent side of the reflex arc for the second component suggests that the fifth nerve is solely concerned.

In light sleep, and in patients heavily sedated with chlorpromazine, both components of the glabella tap reflex have been present, but the second component has always been comparatively large and of fixed latency, with no habituation at all. This is very reminiscent of the work by HernándezPeón and Hagbarth (1955) on the role of the reticular formation on the responses to trigeminal stimulation in the cat.

BLINK REFLEX TO A BRIGHT FLASH OF LIGHT Whether the stimulus was applied to each eye separately or together, the result was a response of the orbicularis oculi which often was of shorter latency on the right side. This phenomenon still remains an unsolved problem, but it may be related to the dominant eye, a factor that so far has been investigated in only a few patients.

When the eye is stimulated in this way, or the optic nerve is stimulated directly in an experimental animal, five waves can be recorded from the optic cortex (Bishop and O'Leary, 1938) and several waves in the E.E.G. over that region (Cigánek, 1958; Cobb and Dawson, 1960). The five waves have been analysed in the cat by Chang and Kaada (1950), who found that the first four deflections were due to activity in geniculo-cortical pathways, and the fifth deflection was due to cortical activity. Chang (1952), however, was able to group anatomically the fibres of the central visual pathways into three groups only, at $1 \mu$, greater than $4 \mu$, and greater than $9 \mu$, so that the recorded waves did not seem to be satisfactorily explained by temporal dispersion along differently conducting fibre tracts.

In man, Cigánek (1961) has separated three primary waves in the E.E.G. response to a bright flash, which began after a latency of $28 \mathrm{msec}$. (Cobb and Dawson (1960) found a latency of $25 \mathrm{msec}$.) and continued over $70 \mathrm{msec}$. It is possible, on the grounds of latency, that the afferents for the blink response to a flash could pass to the cortex first. This might receive some support from the absence of the reflex in a decerebrate child and in a patient with a large meningioma of the occipital region. Unfortunately, this is negative evidence and rather outweighed by the fact that several subjects have been seen who did not blink to the flash, though they had no detectable disorder of the visual system.

Larsson (1956), using the E.E.G. artifact of blink, found that it and the E.E.G. disturbance to a sudden stimulus (the 'startle' reaction) were approximately synchronous. If these observations are confirmable by more refined techniques, it would seem that the blink reflexes would depend primarily upon subcortical pathways.

The failure to demonstrate a conduction deficit of the blink reflexes to flashes of light in patients with unilateral optic atrophy was very disappointing. Most of them (five) did not respond at all when the defective eye was stimulated and, presumably, insufficient receptors could be stimulated to reach the threshold required to elicit the blink reflex. All these patients had demonstrable scotomata in the visual field as well as the ophthalmoscopic appearances of primary optic atrophy. A small group of three patients, who were thought to have a pale optic disc, without a demonstrable scotoma in the corresponding visual field, all gave comparable blink reflexes when the two eyes were separately exposed to the flash.

THE BLINK REFLEX TO A CLICK This reflex was only elicited by loud clicks applied directly over the subject's ear. With a steady rate and intensity of stimulation, it was a relatively stable reflex and only habituated on prolonged stimulation.

The stimulus used to elicit the glabella tap reflex also produced an audible click, but it was possible to show that the same stimulus applied to the vertex did not elicit a blink reflex. It was also clear from the latency response graphs that, in fact, the blink reflex to click and the second component of the glabella tap reflex have different maxima and are therefore different reflexes.

The electronic flash also produced an audible click, but no reflex blink could be elicited if the subject's eyes were completely covered. The latencyresponse graph for flash responses showed very few indeed in the range determined for the click responses. Cobb and Sears (1957) also separated the responses to flash and clicks and their latency figures do not differ much from those of the present study, but as they give no details of their methods and the nature of the stimuli, a comparison is not possible.

\section{CONCLUSIONS}

The characterization of the blink reflexes allows one to measure and study some physiological 
brain-stem pathways, including afferents from the optic nerve, the auditory nerve, the trigeminal nerve and, possibly, the facial nerve. The motor component of the facial nerve supplying the orbicularis oculi muscles is the final common path of all these reflexes. Bilateral simultaneous comparison of latency, size, and behaviour of the blink reflexes may allow one to quantitize partial lesions of some of the cranial nerves or their interconnexions.

In partial unilateral lesions of the seventh, eighth, and fifth cranial nerves an increased latency of the appropriate reflex was observed on the abnormal side. This might be due to complete block or destruction of large nerve fibres by the pathological process, only small nerve fibres being left to conduct the reflex at a siower rate than the normal maximum. Slowing up of conduction velocity through a region of partial block has been postulated as an alternative explanation for the same sort of phenomena in peripheral nerve (Simpson, 1956), without any convincing evidence to support it.

The simultaneous recording of the blink reflex to glabella tap with its two components, one proprioceptive and the other nociceptive, may provide physiological evidence of unilateral exaggeration of one of these naturally conflicting reflexes, related to unilateral brain pathology above the trigeminal sensory nuclei.

The balance of proprioceptive reflexes and avoiding reactions (Denny-Brown, 1956), which make up normal motor behaviour, might possibly be quantitized in the normal response to glabella tap and their imbalance and exaggeration by disease (Denny-Brown and Chambers, 1958) might similarly be measured.

It has certainly been found that in mild hemiplegia, where proprioceptive reflexes tend to be exaggerated elsewhere, the first component of the response to glabella tap is exaggerated, whereas the second component is small, absent, or readily habituated. Similarly, in paralysis agitans, where both proprioceptive and avoiding reactions are exaggerated (Denny-Brown, 1960), both components of the response to glabella tap are very large and of long duration, and habituation of the second component does not occur.

\section{SUMMARY}

Blink reflexes to a bright flash of light, to a loud click, to electrical stimulation of the supra-orbital nerve, to corneal stimulation, and to glabella tap have been studied in health and in disease.

The reflex to glabella tap has two components, an early one with a latency between 11 and $18 \mathrm{msec}$. and a later one between 23 and $46 \mathrm{msec}$.
The behaviour of these components is compatible with the thesis that the first is a proprioceptive reflex and the second nociceptive. Both depend on the integrity of the supra-orbital nerve and the first division of the trigeminal, but in some patients the first component seems to depend on the integrity also of the seventh nerve. It has not been determined whether facial afferents are responsible for this or whether facial (seventh nerve) gamma efferents exist. The role of these would be to maintain proprioceptive sensitivity in sensory organs which discharge along the fifth nerve.

The blink reflex to electrical stimulation of the supra-orbital nerve has also two components and bears a great resemblance to the response to glabella tap, except that the latencies are about $4 \mathrm{msec}$. shorter.

The corneal reflex has shown a wide range of latency from 25 to $40 \mathrm{msec}$. and has been very variable in the same subject. It was present in a decerebrate child.

The blink reflex to a loud click has a latency between 18 and $38 \mathrm{msec}$., with most responses occurring between 23 and $30 \mathrm{msec}$. It, too, was present in a decerebrate child.

The blink reflex to a bright flash of light may contain as many as four components with latencies about $50 \mathrm{msec}$., $64 \mathrm{msec}$., $68 \mathrm{msec}$., and $74 \mathrm{msec}$. No reflex could be elicited in a decerebrate child or in a patient with cortical blindness.

The measurement of the latencies, durations, and amplitudes of these reflexes provides a method of bilateral comparison which may be of use in assessing lesions of the facial nerve, trigeminal nerve, acoustic nerve, and, possibly, optic nerve.

The reflex to glabella tap may be useful in assessing the balance of proprioceptive and avoiding reactions in diseases of the brain such as result in paralysis agitans and hemiplegia.

I am grateful to Dr. Ritchie Russell for his constant encouragement and enthusiasm for this study. He has kindly allowed me to examine most of the patients here reported. I am also grateful to Mr. J. B. Pennybacker, Dr. Charles Whitty, and Dr. Honor Smith for asking me to study some of their patients.

Dr. F. D. Stott kindly loaned the flash apparatus and Mr. M. J. Chester measured the physical characteristics of the flash.

\section{REFERENCES}

Adams, R. D., Denny-Brown, D., and Pearson, C. M. (1953). Diseases of Muscle. A Study in Pathology. Hoeber, New York.

Bishop, G. H., and O'Leary, J. (1938). J. Neurophysiol., 1, 391.

Bruesch, S. R. (1944). J. comp. Neurol., 81, 169.

Carmichael, E. A., and Woollard, H. H. (1933). Brain, 56, 109.

Chang, H-T. (1952). Res. Publ. Ass. nerv. ment. Dis., 30, 430.

- , and Kaada, B. (1950). J. Neurophysiol., 13, 305. 
Cigánek, L. (1958). Rev. neurol., 99, 194. (1961). Electroenceph. clin. Neurophysiol., 13, 165.

Cobb, W. A., and Dawson, G. D. (1960). J. Physiol. (Lond.), 152, 108

-, and Sears, T. A. (1957). Electroenceph. clin. Neurophysiol., 9, 373.

Davis, L. E. (1923). Arch. Neurol. Psychiat. (Chicago), 9, 283.

Denny-Brown, D. (1956). N. C. med. J., 17, 295.

- (1960). Lancet, 2, 1099 and 1155. 36,35 .

Edgeworth, F. H. (1900). J. Anat. (Lond.), 34 (n.s. 14), 113.

Ekbom, K. A., Jernelius, B., and Kugelberg, E. (1952). Neurology, $2,103$.

Foley, J. O., and DuBois, F. S. (1943). J. comp. Neurol., 79, 79.

Gasser, H. S., and Erlanger, J. (1929). Amer. J. Physiol., 88, 581.

Gehuchten, A. van (1906). Anatomie du Système Nerveux de l' Homme, 4th ed., Uystpruyst-Dieudonné, Louvain.

Hernández-Peón, R., and Hagbarth, K-E. (1955). J. Neurophysiol., $18,44$.
Ivy, R. H., and Johnson, L. W. (1907). Univ. Penn. med. Bull., $20,35$. Kugelberg, E. (1952). Brain, 75, 385.

Larsson, L. E. (1956). Electroenceph. clin. Neurophysiol., 8, 631.

Matthews, P. B. C., and Rushworth, G. (1957). J. Physiol. (Lond.), 135, 263.

Oka, M., Tokunaga, A., Murao, T., Yokoi, H,, Okumura, T. Hirata, T., Miyashita, Y., and Yoshitatsu, S. (1958). Med. J. Osaka Univ., 9, 389.

Overend, W. (1896). Lancet, 1, 619.

Rushworth, G. (1960). J. Neurol. Neurosurg. Psychiat., 23, 250.

Simpson, J. A. (1956). Ibid., 19, 275.

Souques, A., and Hartmann, E. (1924). Rev. neurol., 1, 86.

Van Buskirk, C. (1945). J. comp. Neurol., 82, 303

Wakeley, C. P. G., and Edgeworth, F. H. (1933). J. Anat. (Lond.), 67,420 .

Wartenberg, R. (1945). The Examination of Reflexes: A Simplification. Year Book Publishers, Chicago.

Weingrow, S. M. (1933). Arch. Pediat., 50, 234.

Weisenburg, T. H. (1903). Univ. Penn. med. Bull., 16, 63. 